\title{
Teores de nutrientes de dois cultivares de oliveira durante o crescimento vegetativo e o florescimento
}

\author{
Raoni Pereira de Carvalho ${ }^{1}$, Maria do Céu Monteiro da Cruz ${ }^{2}$, Adelson Francisco de Oliveira ${ }^{3}$, \\ Miriã Cristina Pereira Fagundes ${ }^{4}$
}

\section{RESUMO}

Para o planejamento de adubações, visando a manter os níveis de nutrientes adequados para as plantas, é importante monitorar seu estado nutricional durante as diferentes fases de desenvolvimento, sendo a análise foliar o melhor método para avaliar os níveis de nutrientes na planta. Esta pesquisa foi realizada com o objetivo de avaliar os teores de nutrientes em dois cultivares de oliveira, nas fases de crescimento vegetativo e na floração. Foram avaliados espécimes dos cultivares 'Grappolo' e 'Barnea', com dois anos de idade, obtidos a partir do enraizamento de estacas, plantadas no espaçamento de $5 \mathrm{~m}$ entre linhas e $3 \mathrm{~m}$ entre plantas. Utilizou-se o esquema de parcela sub-dividida, tendo na parcela o fatorial $2 \times 2$, sendo duas cultivares e duas fases de emissão fenológicas: plantas com brotações vegetativa e reprodutivas, no delineamento de blocos casualizados, com cinco repetições e sete plantas por parcela. As amostras de folhas foram retiradas em quatro épocas: junho (na ocasião do plantio) e repetidas em agosto, setembro e outubro, quando as plantas iniciaram a emissão de brotações vegetativas e de flores. Na fase de florescimento, a oliveira apresentou menores teores de nutrientes que as plantas em fase vegetativa. O cultivar 'Barnea', por seu hábito de crescimento rápido, apresentou menores teores de nutrientes, durante as fases vegetativa e reprodutiva.

Palavras-chave: Olea europaea L, estado nutricional, 'Grappolo', 'Barnea', adubação.

\section{ABSTRACT}

\section{Nutrient content of two olive cultivars during the vegetative growth and flowering}

The monitoring of the nutritional status during the different development stages of the plant is important for planning the fertilization, in order to maintain the nutrients in appropriate levels, and the leaf analysis is the best method to evaluate the nutrients levels in plants. Thus, the present study aimed to evaluate the nutrients contents in two olive cultivars during vegetative growth and flowering. Two-year-old olive cultivars 'Grappolo' and 'Barnea', obtained from rooting, planted at a spacing of $5 \mathrm{~m}$ between rows and $3 \mathrm{~m}$ between plants were evaluated. The statistical design was randomized blocks in Split Plot scheme, with 2 × 2 factorial on plot, two cultivars and two phenological stages: plants with vegetative and reproductive shoots, with five replicates and seven plants per plot. The leaf samples were harvested in four seasons: June (at the time of planting) August, September and October when plants began the emission of vegetative shoots and flowers. During the flowering period, the olive tree showed lower nutrients levels than the plants in vegetative stage. The cultivar 'Barnea', due to its fast growth, showed lower nutrients levels during the vegetative and reproductive stages.

Key words: Olea europaea L, nutritional status, 'Grappolo', 'Barnea', fertilizer.

Recebido para publicação em 14/03/2012 e aprovado em 19/03/2013.

'Engenheiro-Agrônomo. Departamento de Agronomia, Universidade Federal dos Vales Jequitinhonha e Mucuri, Rodovia MGT 367, Km 583, 5000, 39100-000, Diamantina, Minas Gerais, Brasil. raonipc@ hotmail.com

2Engenheira-Agrônoma, Pós - Doutora., Departamento de Agronomia, Universidade Federal dos Vales Jequitinhonha e Mucuri, Rodovia MGT 367, Km 583, 5000, 39100-000, Diamantina, Minas Gerais, Brasil. mariceu@ufvjm.edu.br

${ }^{3}$ Engenheiro-Agrônomo, Doutor. Empresa de Pesquisa Agropecuária de Minas Gerais, U. R. Sul de Minas, Caixa Postal 176, 37200-000, Lavras, Minas Gerais, Brasil. adelson@)epamig.ufla.br

${ }^{4}$ Engenheira-Agrônoma. Departamento de Agronomia, Universidade Federal dos Vales Jequitinhonha e Mucuri, Rodovia MGT 367, Km 583, 5000, 39100-000, Diamantina. Minas Gerais, Brasil. miria.agro@yahoo.com.br 


\section{INTRODUÇÃO}

A oliveira (Olea europaea L.) é considerada uma espécie rústica quanto ao manejo nutricional, apresentando baixo requerimento de nutrientes em relação a outras espécies frutíferas (Chatzistathis et al., 2009). Porém, a adubação é uma prática de manejo fundamental para o cultivo desta espécie, pois os nutrientes desempenham um papel-chave no seu metabolismo e, consequentemente, no seu crescimento e reprodução (Freihat \& Masa`Deh, 2006).

Sendo assim, a oliveira deve receber doses adequadas de nutrientes, desde os estádios iniciais, para que não ocorra desequilíbrio entre o conteúdo mineral e o incremento de matéria seca, estimulando a formação de folhas sadias e, futuramente, de inflorescências, já que essas ocorrem nas axilas das folhas (Bouranis et al., 2001; Livramento \& Oliveira, 2006).

Durante o período de floração, deve-se ter maior atenção quanto à fertilização, já que muitos elementos tornam-se potencialmente limitantes nessa fase. Há competição por nutrientes no broto vegetativo de cada folha para se iniciar a indução floral, pois ocorrem, simultaneamente, o crescimento de ramos vegetativos e o crescimento das partes reprodutivas (Bouranis et al., 2001).

Assim, para se realizar um programa eficiente de adubação, é importante considerar as características do cultivar implantado, relacionadas com o seu hábito de crescimento, com a sua capacidade de extração de nutrientes do solo e com a sua produtividade (López-Granados et al., 2004; Chouliaras et al., 2009). Também, deve-se considerar as características do local de cultivo, fator de grande influência na absorção de nutrientes pela planta (Chatzistathis et al., 2010).

Já foi relatada diferença entre cultivares em relação à absorção e utilização de nutrientes, como nitrogênio, fósforo e potássio (Dimassi et al., 1999; Bouranis et al., 2001; Freihat \& Masa’Deh, 2006). Chatzistathis et al. (2009), trabalhando com dois cultivares de oliveira, encontraram diferenças entre a eficiência de uso de $\mathrm{Mn}$ e Fe. A época de amostragem também influencia na composição nutricional das folhas (Freihat \& Masa 'Deh, 2006).

Para avaliar os teores de nutrientes nas plantas, o melhor método que se tem é a análise foliar, pela qual se possibilita detectar os teores baixos/altos dos nutrientes na folha, antes que apareçam os sintomas de deficiência/toxidez (Fernández-Escobar, 2008; Chatzistathis et al., 2010).

O presente trabalho foi realizado com o objetivo de avaliar os teores de nutrientes de dois cultivares de oliveira nas fases vegetativa e reprodutiva.

\section{MATERIAL E MÉTODOS}

A pesquisa foi conduzida, em condições de campo, no município de Diamantina, MG, situado a $18^{\circ} 14^{\prime} 56^{\prime \prime} \mathrm{S} \mathrm{e} 43^{\circ}$
36' 0" W, com altitude de $1.384 \mathrm{~m}$. O clima da região é do tipo Cwb, segundo classificação de Köppen, temperado úmido, com inverno seco e chuvas no verão. O solo da área do experimento é classificado como Neossolo Quartzarênico distrófico e os dados de temperatura e precipitação que ocorreram na região durante o período experimental estão apresentados na Figura 1.

Utilizou-se o esquema de parcela sub-dividida, tendo na parcela o fatorial $2 \times 2$, sendo duas cultivares e duas fases fenológicas: plantas com brotações vegetativa e reprodutivas, no delineamento em blocos casualizados, com cinco repetições e sete plantas por parcela e as avaliações realizadas em quatro épocas distintas: junho (ocasião do plantio), agosto, setembro e outubro. Por ocasião da análise, a amostragem de junho foi avaliada separadamente.

As mudas de oliveira, com dois anos de idade, propagadas por enraizamento de estacas, foram plantadas no espaçamento de $5 \mathrm{~m}$ entre linhas e $3 \mathrm{~m}$ entre plantas. Por ocasião do plantio foi realizada a correção do solo, com a aplicação de calcário e a adubação das covas, abertas nas dimensões de 0,50 x 0,50 x 0,50 m, de acordo com a análise de solo (Tabela 1), com esterco bovino (20 L por cova), fósforo (com aplicação de super fosfato simples), potássio (com aplicação de cloreto de potássio). A adubação nitrogenada foi parcelada em três aplicações, nos meses de setembro, novembro e janeiro. Aos oito meses após o plantio, retiraram-se, após a amostragem foliar, amostras de solo para determinar seus teores de nutrientes (Tabela 2).

Realizou-se o manejo das plantas daninhas, periodicamente, conforme a incidência nas áreas de cultivo. Para isso foi realizada roçagem entre as linhas e capina manual na projeção da copa. O monitoramente de pragas e doenças foi realizado de acordo com a recomendação para a cultura.

Para avaliar o crescimento das plantas, foi medido o diâmetro do caule, na altura de $20 \mathrm{~cm}$ do nível do solo, a altura das plantas $(\mathrm{H})$, a partir do nível do solo até o final do ramo mais alto e o volume de copa (VC), calculado por meio da fórmula: $\mathrm{VC}=\pi \mathrm{D}^{2} \mathrm{H} / 6$, em que o diâmetro médio da copa: $\mathrm{D}=(\mathrm{DI}+\mathrm{D} 2) / 2$, $\mathrm{D} 1$ e D2 correspondem à menor e à maior largura da copa $\mathrm{e} \mathrm{H}=$ altura da planta. A partir desses dados foram calculados os incrementos no crescimento em altura, diâmetro e volume de copas dos cultivares na área de cultivo, por meio das diferenças observadas após o transplantio das mudas no campo.

Foram retiradas amostras de folhas nas plantas antes do transplantio, no mês de junho, para verificar o estado nutricional das mudas antes do cultivo na área. As amostras foram compostas por cerca de 40 a 60 folhas com pecíolo, retiradas no terço mediano dos ramos. A amostragem foi 
repetida em agosto, setembro e outubro, quando de plantas iniciaram a emissão de brotações vegetativas e de flores. Assim, foram amostradas plantas somente em estágio vegetativo $(\mathrm{BV})$ ou em florescimento $(\mathrm{F})$.

O material vegetal foi lavado e colocado para secar em estufa, com circulação forçada de ar, a $60{ }^{\circ} \mathrm{C}$, até atingir massa constante. Em seguida, foi realizada a análise foliar, utilizando-se a digestão nítrico-perclórica, para determinação dos teores, de fósforo, por colorimetria, e, de potássio, por fotometria de chama. O nitro- gênio total foi determinado pelo método Kjeldhal, após digestão sulfúrica, conforme descrito por Malavolta et al. (1997). Os teores de Ca, Mg, Zn, Cu, Fe e Mn foram determinados por espectrofotometria de absorção atômica.

Os dados obtidos foram submetidos à análise de variância e comparação de médias pelo teste $\mathrm{F}$, a 5\% de probabilidade de erro, para comparar os teores de nutrientes durante o crescimento vegetativo e reprodutivo dos cultivares de oliveira, nas condições estudadas.

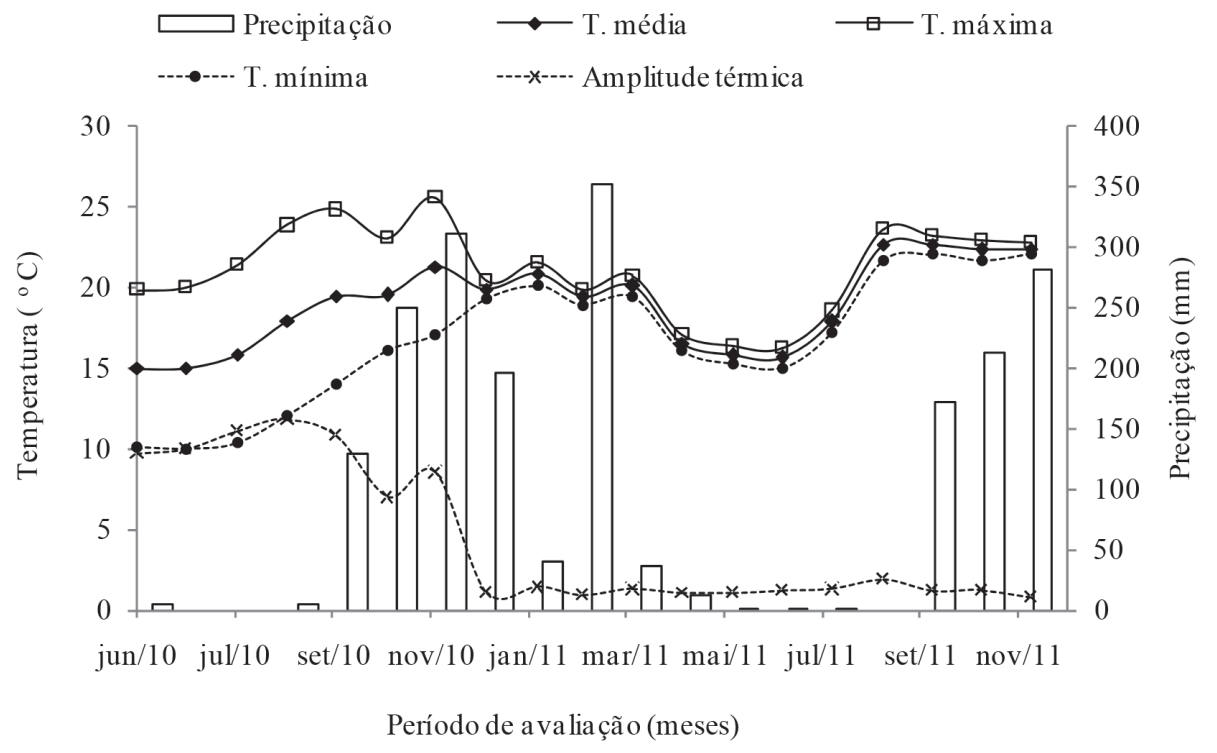

Figura 1. Médias mensais da temperatura máxima (T. máxima), temperatura média (T. média), temperatura mínima (T. mínima), amplitude térmica e precipitação que ocorreram na região de Diamantina, MG durante o período experimental. Fonte: INMET.

Tabela 1. Análise química do solo da área experimental na profundidade de 0 a 20 e 21 a $40 \mathrm{~cm}$, na época do plantio dos cultivares de oliveira no campo, Diamantina, MG

\begin{tabular}{|c|c|c|c|c|c|c|c|}
\hline \multirow{2}{*}{$\begin{array}{l}\text { Profundidade } \\
\text { (cm) }\end{array}$} & \multirow{2}{*}{$\begin{array}{c}\mathrm{pH} \\
\mathrm{H}_{2} \mathrm{O}\end{array}$} & $\mathbf{P}$ & $\mathbf{K}$ & $\mathrm{Ca}$ & Mg & $\mathrm{Al}^{+3}$ & $\mathbf{H}+\mathbf{A l}$ \\
\hline & & \multicolumn{2}{|c|}{$\mathrm{mg} \mathrm{dm}^{-3}$} & \multicolumn{4}{|c|}{$\mathrm{cmol}_{\mathrm{c}} \mathrm{dm}^{-3}$} \\
\hline $0-20$ & 5,2 & 1,6 & 22 & 0,6 & 0,2 & 0,6 & 3,7 \\
\hline $21-40$ & 5,1 & 2,4 & 14 & 0,5 & 0,2 & 1,0 & 3,3 \\
\hline \multirow{2}{*}{$\begin{array}{l}\text { Profundidade } \\
\text { (cm) }\end{array}$} & SB & $t$ & $\mathbf{T}$ & $\mathbf{V}$ & $\mathbf{m}$ & M.O & Areia \\
\hline & \multicolumn{3}{|c|}{$\mathrm{cmol}_{\mathrm{c}} \mathrm{dm}^{-3}$} & \multicolumn{2}{|c|}{$\%$} & \multicolumn{2}{|c|}{ dag kg ${ }^{-1}$} \\
\hline $0-20$ & 0,9 & 1,5 & 4,6 & 19,0 & 41,0 & 1,2 & 83 \\
\hline $21-40$ & 0,7 & 1,7 & 4,0 & 18,0 & 58,0 & 0,8 & 83 \\
\hline
\end{tabular}

${ }^{1}$ SB soma de bases; t- CTC efetiva; T- CTC a pH 7,0; V - saturação de bases; $\mathrm{m}$ - índice de saturação de alumínio

Tabela 2. Análise química do solo da área experimental na profundidade de 0 a $20 \mathrm{~cm}$, aos oito meses após o plantio dos cultivares de oliveira no campo, Diamantina, MG

\begin{tabular}{|c|c|c|c|c|c|c|c|}
\hline \multirow{2}{*}{$\begin{array}{l}\text { Profundidade } \\
(\mathrm{cm})\end{array}$} & \multirow{2}{*}{$\begin{array}{c}\mathrm{pH} \\
\mathrm{H}_{2} \mathrm{O}\end{array}$} & $\mathbf{P}$ & $\mathbf{K}$ & $\mathbf{C a}$ & Mg & $\mathrm{Al}^{+3}$ & $\mathbf{H}+\mathbf{A l}$ \\
\hline & & \multicolumn{2}{|c|}{$\mathrm{mg} \mathrm{dm}^{-3}$} & \multicolumn{4}{|c|}{$\mathrm{cmol}_{\mathrm{c}} \mathrm{dm}^{-3}$} \\
\hline $0-20$ & 6,2 & 12,59 & 30,7 & 1,36 & 0,44 & 0,01 & 1,50 \\
\hline \multirow{2}{*}{$\begin{array}{l}\text { Profundidade } \\
(\mathrm{cm})\end{array}$} & SB & $\mathbf{t}$ & $\mathbf{T}$ & $\mathbf{V}$ & $\mathbf{m}$ & M.O & Areia \\
\hline & \multicolumn{3}{|c|}{$\mathrm{cmol}_{\mathrm{c}} \mathrm{dm}^{-3}$} & \multicolumn{2}{|c|}{$\%$} & \multicolumn{2}{|c|}{ dag kg-1 } \\
\hline $0-20$ & 1,88 & 1,89 & 3,38 & 56,0 & 1,0 & 1,2 & 79 \\
\hline
\end{tabular}

${ }^{1}$ SB soma de bases; t- CTC efetiva; T- CTC a pH 7,0; V - saturação de bases; $\mathrm{m}$ - índice de saturação de alumínio 


\section{RESULTADOS E DISCUSSÃO}

Observou-se interações entre as fases fenológicas e os cultivares para todos os nutrientes avaliados e entre as épocas de avaliação e as cultivares e entre as fases fenolóficas e as épocas (Tabela 3). Dessa forma, optou-se por apresentar as diferenças observadas nos teores de nutrientes entre os cultivares na ocasião do plantio (junho) e nas amostragens realizadas em agosto, setembro e outubro. Foi realizada também comparação dos teores de nutrientes em plantas durante a fase de crescimento vegetativo e reprodutiva nos dois cultivares, separadamente, nas épocas distintas, visto que as variações observadas com o início da floração e crescimento vegetativo já são conhecidas, identificando as diferenças existentes entre os estágios fenológicos.

Nos resultados da análise foliar, na ocasião do plantio, o cultivar 'Barnea' apresentou maiores teores de N, K e S, quando comparados com os do cultivar 'Grappolo', que teve maiores teores de B, Fe, Mn e Zn (Tabela 4). Essa variação entre os cultivares pode ser atribuída às diferenças nas características genotípicas, como, proporção de crescimento de raiz, eficiência na absorção de nutrientes e, ou, eficiência fotossintética (Dimassi et al., 1999; Bouranis et al., 2001; Freihat \& Masa'Deh, 2006).

Nas avaliações realizadas em agosto, setembro e outubro o cultivar 'Grappolo' apresentou maiores teores de $\mathrm{N}, \mathrm{P}, \mathrm{K}, \mathrm{B}, \mathrm{Cu}, \mathrm{Fe}$ e Zn, comparados com os do cultivar 'Barnea'. Além disso, os teores de todos os nutrientes foram superiores àqueles verificados antes do transplantio das mudas, com exceção do P, apenas para 'Barnea' (Tabela 5). Esse comportamento pode ser atribuído ao menor crescimento das plantas do cultivar 'Grappolo', comparado com o da 'Barnea', que apresentaram maior incremento no crescimento do diâmetro do caule e altura das plantas, o que correspondeu ao maior volume de copa, aos oito meses após o plantio (Tabela 6).

A influência do hábito de crescimento sobre o aproveitamento de nutrientes pela planta já foi relatada em plantas do cultivar 'Nabali', que apresentou maiores teores de $\mathrm{N}, \mathrm{P}$ e K, quando comparados com os de outros cultivares, o que é justificado por seu hábito de crescimento lento, levando ao maior teor de nutrientes por esse cultivar (Freihat \& Masa'Deh, 2006).

Associado a isso, houve melhoria do solo, após o plantio das mudas em campo, pois, observando-se as propriedades do solo, no momento do plantio (Tabela 1) e aos oito meses após (Tabela 2), verifica-se que todas as características químicas analisadas melhoraram após a correção e adubação, o que contribuiu para aumentar a disponibilidade de nutrientes para as plantas, em decorrência da elevação do $\mathrm{pH}$ do solo, próximo à neutralidade, valor em que a oliveira tem maior aproveitamento de nutrientes (Cabral, 2009).

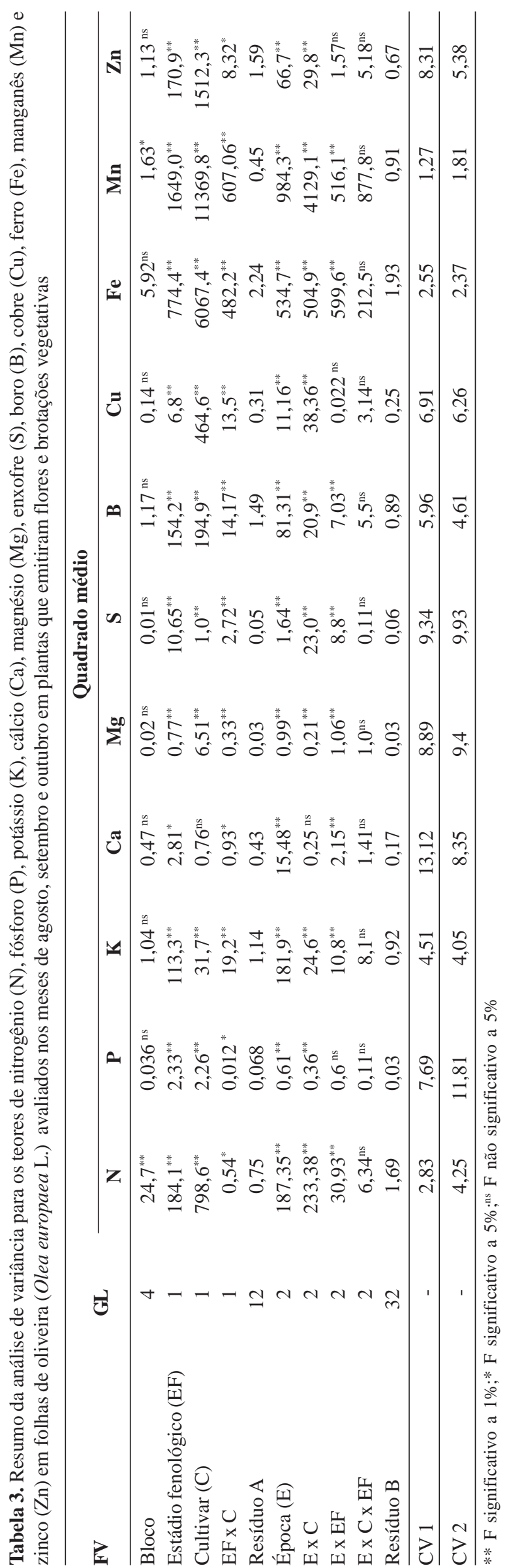

Rev. Ceres, Viçosa, v. 60, n.4, p. 569-576, jul/ago, 2013 
Ao se compararem os teores de nutrientes, durante as fases de emissão de brotações vegetativas ou reprodutivas, verificaram-se, nas amostras do cultivar 'Barnea', menores teores de $\mathrm{N}$ e $\mathrm{K}$ em plantas em florescimento, de $\mathrm{P}$ e de $\mathrm{Ca}$, em plantas floridas em setembro e outubro, de $\mathrm{S}$, em plantas floridas outubro e, durante toda a fase de floração, de todos os micronutrientes, com exceção do cobre (Tabela 7).
O comportamento observado do ‘Grappolo' foi semelhante ao do cultivar 'Barnea' diferindo apenas em relação às épocas, pois, com o florescimento, as plantas apresentaram menores teores de N, P e K, em todas as épocas avaliadas, menores teores de $\mathrm{Ca}$ e $\mathrm{Mg}$, em setembro, e de $\mathrm{S}$, em setembro e outubro. Em relação aos micronutrientes, os menores teores de $\mathrm{B}, \mathrm{Cu}$ e $\mathrm{Mn}$ foram determinados também em plantas floridas em setembro, os de Fe em

Tabela 4. Teores de nutrientes em folhas de oliveira (Olea europaea L.) 'Grappolo'e 'Barnea', com dois anos de idade, avaliados na ocasião do plantio (junho) na área de cultivo em Diamantina, MG

\begin{tabular}{|c|c|c|c|c|c|c|c|}
\hline \multirow{2}{*}{ Cultivares } & $\mathbf{N}$ & $\mathbf{P}$ & & $\mathbf{K}$ & Ca & Mg & $\mathbf{S}$ \\
\hline & \multicolumn{7}{|c|}{$\left(\mathrm{g} \mathrm{kg}^{-1}\right)$} \\
\hline 'Barnea' & $24,0 \mathrm{a}$ & $1,73 \mathrm{a}$ & & $23,0 \mathrm{a}$ & $2,28 \mathrm{a}$ & $2,64 \mathrm{a}$ & $2,44 \mathrm{a}$ \\
\hline 'Grappolo' & $21,8 \mathrm{~b}$ & $1,02 \mathrm{a}$ & & $19,6 \mathrm{~b}$ & $2,66 \mathrm{a}$ & $2,23 \mathrm{a}$ & $1,14 \mathrm{~b}$ \\
\hline \multirow[t]{3}{*}{$\overline{\mathrm{CV}(\%)}$} & 2,3 & 4,5 & & 2,8 & 4,6 & 2,23 & 1,96 \\
\hline & \multicolumn{2}{|c|}{ B } & $\mathrm{Cu}$ & \multicolumn{2}{|c|}{$\mathrm{Fe}$} & Mn & Zn \\
\hline & \multicolumn{7}{|c|}{$\left(\mathrm{mg} \mathrm{kg}^{-1}\right)$} \\
\hline 'Barnea' & \multicolumn{2}{|c|}{$11,02 \mathrm{~b}$} & $3,04 \mathrm{a}$ & \multicolumn{2}{|c|}{$23,8 \mathrm{~b}$} & $50,7 \mathrm{~b}$ & $6,59 \mathrm{~b}$ \\
\hline 'Grappolo' & \multicolumn{2}{|c|}{$23,45 \mathrm{a}$} & $2,85 \mathrm{a}$ & \multicolumn{2}{|c|}{$36,1 \mathrm{a}$} & $95,1 \mathrm{a}$ & $15,07 \mathrm{a}$ \\
\hline$\overline{\mathrm{CV}(\%)}$ & \multicolumn{2}{|c|}{3,03} & 5,95 & \multicolumn{2}{|c|}{16,86} & 17,4 & 5,44 \\
\hline
\end{tabular}

*Médias seguidas de letras diferentes na coluna, para cada variável, diferem entre si pelo teste $\mathrm{F}$, a $5 \%$ de probabilidade.

Tabela 5. Teores de nutrientes em folhas de oliveira (Olea europaea L.) 'Grappolo' (G) e 'Barnea' (B) avaliados nos meses de agosto, setembro e outubro, em Diamantina, MG

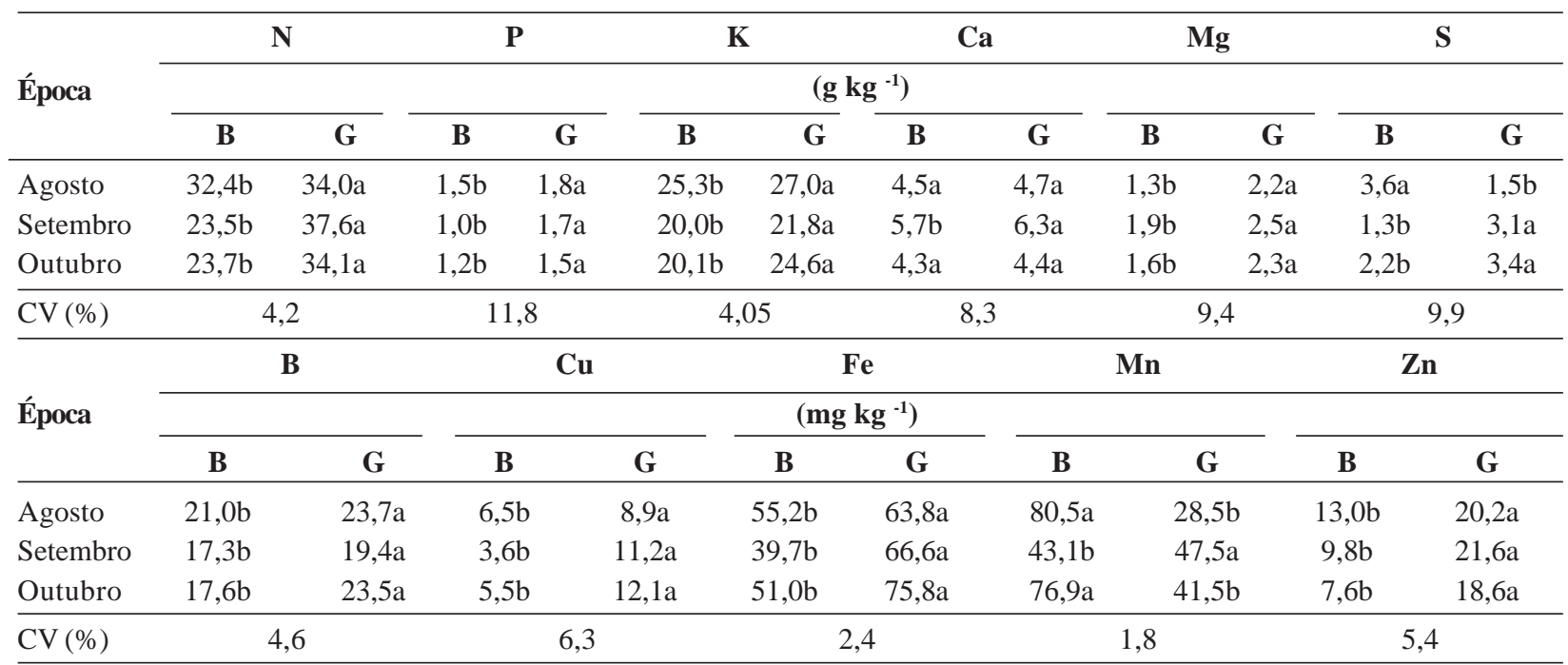

*Médias seguidas de letras diferentes na linha, para cada variável, diferem entre si pelo teste $\mathrm{F}$ a $5 \%$ de probabilidade.

Tabela 6. Incremento no diâmetro do caule, altura de plantas e volume de copa aos quatro e oito meses após o plantio dos cultivares de oliveira (Olea europaea L.) em Diamantina, MG

\begin{tabular}{lcccccc}
\hline \multirow{2}{*}{ Meses } & \multicolumn{2}{c}{ Diâmetro do caule $(\mathbf{m m})$} & \multicolumn{2}{c}{ Altura $(\mathbf{c m})$} & \multicolumn{2}{c}{ Volume de copa $\left(\mathbf{m}^{3}\right)$} \\
\cline { 2 - 7 } & 'Grappolo' & 'Barnea' & 'Grappolo' & 'Barnea' & 'Grappolo' & 'Barnea' \\
\hline Quatro & $1,73 \mathrm{~b}$ & $2,11 \mathrm{a}$ & $13,01 \mathrm{~b}$ & $18,1 \mathrm{a}$ & $0,42 \mathrm{~b}$ & $0,56 \mathrm{a}$ \\
Oito & $3,79 \mathrm{~b}$ & $4,08 \mathrm{a}$ & $8,0 \mathrm{~b}$ & $9,5 \mathrm{a}$ & $0,45 \mathrm{~b}$ & $1,07 \mathrm{a}$ \\
Total & $5,52 \mathrm{~b}$ & $6,19 \mathrm{a}$ & $21,01 \mathrm{~b}$ & $27,6 \mathrm{a}$ & $0,87 \mathrm{~b}$ & $1,63 \mathrm{a}$ \\
\hline $\mathrm{CV}(\%)$ & \multicolumn{2}{c}{5,5} & & 15,3 \\
\hline
\end{tabular}

*Médias seguidas de letras diferentes na linha, para cada variável, diferem entre si pelo teste $\mathrm{F}$, a $5 \%$ de probabilidade. 
setembro e outubro e os de Zn, em agosto e setembro (Tabela 8).

As diferenças observadas entre os teores de nutrientes, nas fases vegetativa e reprodutiva nas épocas amostradas, podem ser atribuídas às transformações que ocorrem durante o processo de florescimento. Bouranis et al. (2001) observaram que a proporção entre os teores de $\mathrm{N}$ e $\mathrm{P}$ de folha e broto reprodutivo aumentou ou permaneceu constante antes da diferenciação floral, enquanto, durante a diferenciação floral e na fase seguinte, essa proporção diminuiu.

Com relação aos menores teores de macronutrientes observados durante a fase de floração, possivelmente ocorreram por causa da maior utilização destes pelas plantas para o desenvolvimento das inflorescências, pois ocorre a translocação de assimilados para a sua formação, gerando, assim, concorrência por nutrientes entre os drenos (Connor \& Fereres, 2005).

$\mathrm{O} \mathrm{N}$ é um elemento bastante requerido pela oliveira para o crescimento das brotações floríferas; o $\mathrm{P}$ tem proporcionado maiores níveis de floração e frutificação; o K é relatado como o macronutriente com maior efeito positivo sobre a floração da oliveira, por estimular a indução floral e, além disso, é fundamental na qualidade dos frutos (Mesquita et al., 2006; Erel et al., 2008). O Ca e o Mg estimulam o desenvolvimento de folhas e raízes, sendo o primeiro constituinte dos pectatos de Ca da lamela média e é o segundo constituinte da clorofila (Paulus, 2011).

As diferenças em relação ao boro podem ser atribuídas à participação desse nutriente no florescimento, pois o boro é fundamental para a formação de gemas florais, e desenvolvimento dos frutos. Delgado et al. (1994) observou redução nos teores de boro no momento da antese, em decorrência da alta quantidade que é mobilizada para a formação das flores e frutos. Provavelmente, por isso, neste experimento, as diferenças ocorreram a partir do mês de setembro, época do pleno florescimento dos dois cultivares.

Com relação aos menores teores de $\mathrm{Zn}, \mathrm{Cu}$ e $\mathrm{Mn}$, durante a fase de floração, devem-se ao fato de esses micronutrientes participarem no processo de crescimento reprodutivo, atuando na indução ao florescimento, polinização e estabelecimento do fruto (Kirkby \& Römhel, 2007).

A importância dos micronutrientes no processo reprodutivo foi notada neste estudo, visto que os cultivares 'Barnea' e 'Grappolo' apresentaram menores teores durante a floração (Tabelas 6 e 7), o que evidencia a maior demanda desses nutrientes nessa fase.

Apesar dos menores teores de nutrientes observados durante a emissão de flores, o estado nutricional dos cultivares de oliveira apresentava teores semelhantes aos considerados adequados para a cultura (Fernández-

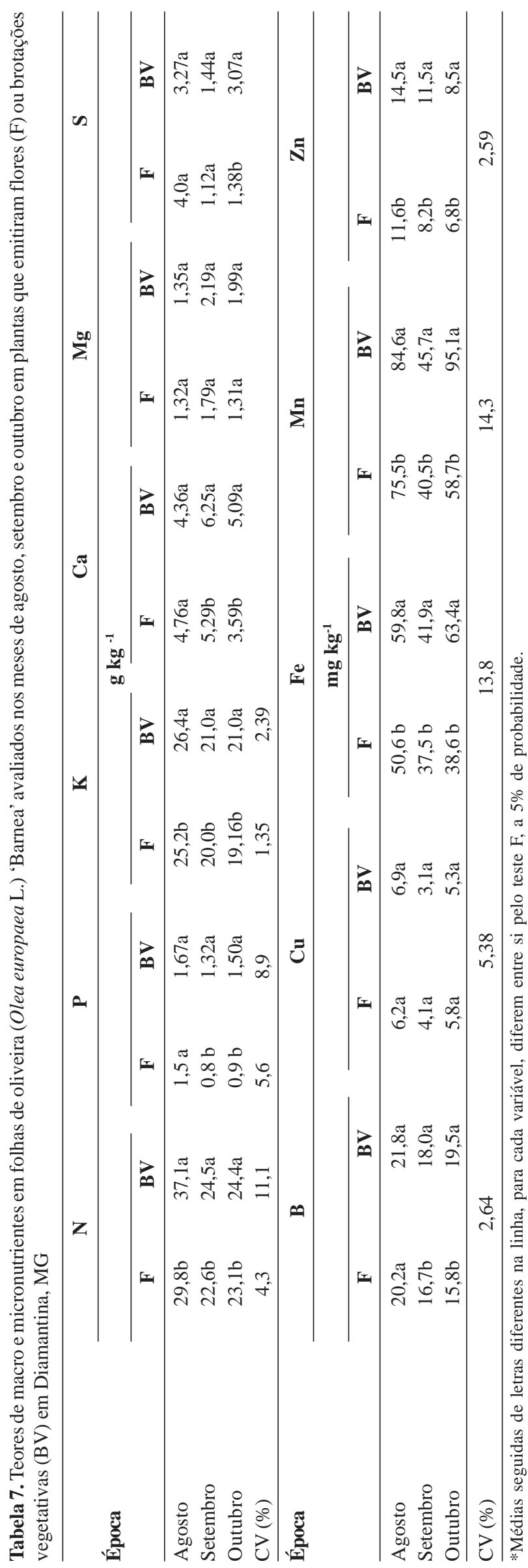

Rev. Ceres, Viçosa, v. 60, n.4, p. 569-576, jul/ago, 2013 


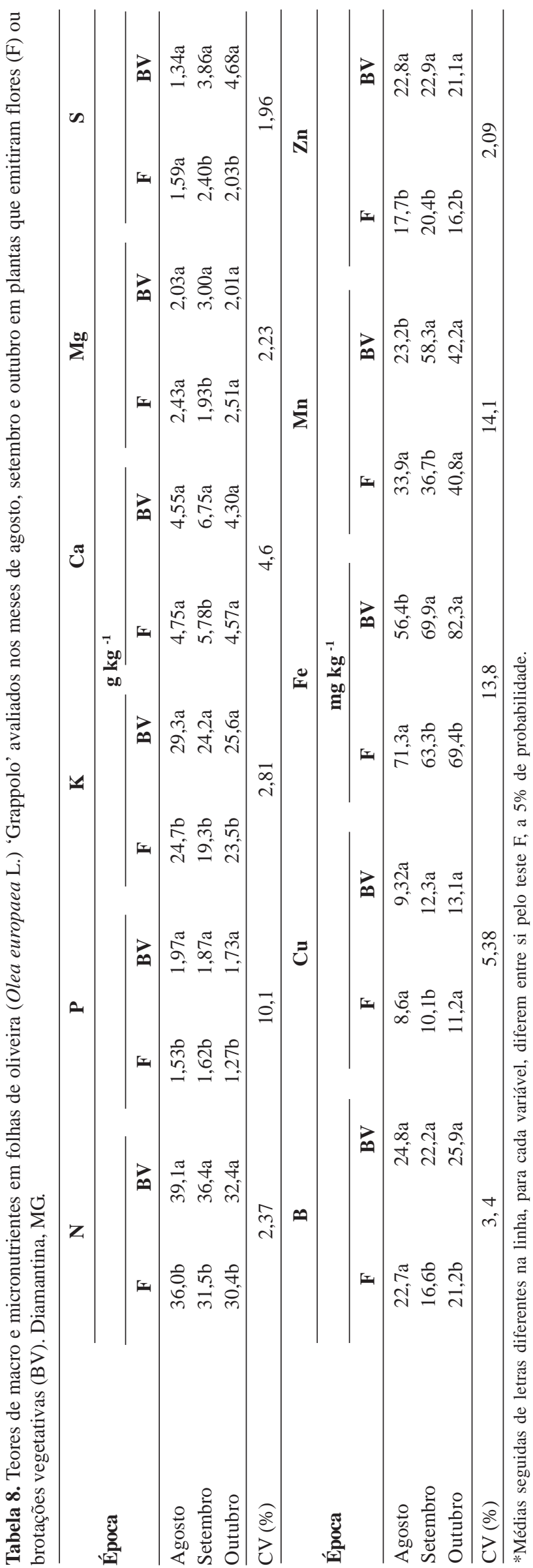

Escobar, 2008) e aos que vêm sendo observados em cultivares plantados em algumas regiões produtoras no Brasil (Mesquita et al., 2012). Entretanto, deve-se considerar que as plantas estavam numa área recém- preparada e, em se tratando de espécie perene, ao longo dos anos, as adubações devem ser bem planejadas, para que não se comprometa a produção, vista a elevada demanda por nutrientes durante o florescimento, pois sua escassez pode levar a distúrbios fisiológicos que prejudicam o desenvolvimento e a produção. Além disso, o comportamento observado em relação à utilização dos nutrientes pelos cultivares, durante o crescimento reprodutivo, é importante, para orientar o parcelamento da adubação da oliveira, que tem apresentado crescimento da área cultivada no Brasil.

\section{CONCLUSÕES}

Oliveiras apresentam menores teores de nutrientes nas folhas na fase de florescimento do que na fase vegetativa.

O cultivar 'Barnea', por seu hábito de crescimento rápido, apresenta menores teores de nutrientes, durante as fases vegetativa e reprodutiva do que o cultivar Grappolo.

\section{REFERÊNCIAS}

Bouranis DL, Zakynthinos G, Kapetanos C, Chorianopoulou SN, Kitsaki C \& Drossopoulos JB (2001) Dynamics of nitrogen and phosphorus partition in four olive tree cultivars during bud differentiation. Journal of Plant Nutrition, 24:1535-1550.

Cabral EC (2009) Estudos preliminares de polinização de oliveira (Olea europaea L.) cv. Galega vulgar. Tese de Mestrado. Instituto Superior de Agronomia, Universidade Técnica de Lisboa, Lisboa. $75 \mathrm{p}$.

Chatzistathis Th, Therios I, Alifragis D \& Dimassi K (2010) Effect of sampling time and soil type on $\mathrm{Mn}, \mathrm{Fe}, \mathrm{Zn}, \mathrm{Ca}, \mathrm{Mg}$, $\mathrm{K}$ and $\mathrm{P}$ concentrations of olive (Olea europaea L., cv. 'Koroneike') leaves. Scientia Horticulturae, 126:291-296.

Chatzistathis Th, Therios I \& Alifragis D (2009) Differential uptake, distribution within tissues, and use efficiency of manganese, iron, and zinc by olive cultivars Kothreiki and Koroneike. HortScience, 44:1994-1999.

Chouliaras V, Tasioula M, Chatzissavvidis C, Therios I \& Tsabolatidou E (2009) The effects of a seaweed extract in addition to nitrogen and boron fertilization on productivity, fruit maturation, leaf nutritional status and oil quality of the olive (Olea europaea L.) cultivar Koroneike. Journal of the Science of Food and Agriculture, 89:984-988.

Connor DJ \& Fereres E (2005) The physiology of adaptation and yield expression in olive. Horticultural Reviews, 31:157231.

Delgado A, Benlloch M \& Fernández-Escobar R (1994) Mobilization of boron in olive trees during flowering and fruit development. HortScience, 29:616-618.

Dimassi K, Therios I \& Passalis A (1999) Genotypic effect on leaf mineral levels of 17 olive cultivars grown in Greece. Acta Horticulturae, 474: 329-331. 
Erel R, Dag A, Ben-Gal A, Schwartz A \& Yermiyahu U (2008) Flowering and fruit set of olive trees in response to nitrogen, phosphorus and potassium. Journal of the American Society fot Horticultural Science, 133:639-647.

Fernández-Escobar R (2008) Fertilización. In: Barranco D, Férnandez-Escobar, R \& Rallo L (Eds.) El cultivo del olivo. Madrid, Mundi-Prensa. p. 297-336.

Freihat NM \& Masa'Deh YK (2006) Response of two-year-old trees of four Olive cultivars to fertilization. American-Eurasian Journal Agriculture \& Environmental Science, 1:185-190.

Kirkby E \& Römhel V (2007) Micronutrientes na fisiologia de plantas: funções, absorção e mobilidade. International Plan Nutrition Institute. 24p. (Encarte técnico: Informações Agronômicas, $\left.\mathrm{n}^{\circ} 118\right)$.

Livramento DE \& Oliveira AF (2006) Ecofisiologia da oliveira, alguns aspectos de fotossíntese, temperatura e radiação solar. Azeitona e azeite de oliva: tecnologias de produção. Informe Agropecuário, 27:27-32.
López-Granados F, Jurado-Expósito M, Álamo S \& García-Torres L (2004) Leaf nutrient spatial variability and site-specific fertilization maps within olive (Olea europaea L.) orchards. European Journal of Agronomy, 21:209 - 222.

Malavolta E, Vitti GC \& Oliveira SA (1997) Avaliação do estado nutricional das plantas: princípios e aplicações. Piracicaba, POTAFOS. 319 p.

Mesquita HA, Fráguas JC \& Paula MB (2006) Adubação e nutrição de oliveira. Azeitona e azeite de oliva: tecnologias de produção. Informe Agropecuário, 27: 68-72.

Mesquita HA, García CN \& Costa EL (2012) Solos, aspectos nutricionais e sugestões de fertilização. In: Oliveira AF (Ed.). Oliveira no Brasil: tecnologias de produção. Belo Horizonte, EPAMIG. p. 385-432.

Paulus E (2011) Avaliação do crescimento inicial de oliveira "Arbequina" em diferentes manejos do solo e dosagens de fósforo. Tese de Mestrado. Universidade Federal de Santa Maria, Santa Maria. 83p. 